\title{
Latex allergy: epidemiological study of 1351 hospital workers
}

Gary M Liss, Gordon L Sussman, Ken Deal, Shirley Brown, Maureen Cividino, Sidney Siu, Donald H Beezhold, Gordon Smith, Mark C Swanson, John Yunginger, Andrew Douglas, D Linn Holness, Phyllis Lebert, Paul Keith, Susan Wasserman, Kristiina Turjanmaa

Ontario Ministry of Labour, Ontario, Canada

G M Liss

S Siu

G Smith

Department of Preventive Medicine and Biostatistics, University of Toronto, Toronto, Canada $\mathrm{G} M$ Liss

Division of Allergy, Wellesley Hospital, University of Toronto, Toronto, Ontario, Canada

G L Sussman

Michael G DeGroot School of Business, McMaster University, Hamilton, Ontario, Canada

K Deal

Employee Health Service, Hamilton Civic Hospitals, Hamilton, Ontario, Canada

$S$ Brown

M Cividino

Guthrie Research Institute, Sayre, Pennsylvania, USA

D H Beezhold

Allergic Diseases Research Laboratory, Mayo Clinic,

Rochester, Minnesota, USA

M C Swanson

$\mathrm{J}$ Yunginger

Medical Devices

Bureau, Health

Canada, Ottawa,

Ontario, Canada

A Douglas

Department of Occupational and

Environmental Health,

St Michael's Hospital,

University of Toronto,

Toronto, Ontario,

Canada

D L Holness

Department of

Medicine, McMaster University, Hamilton,

Ontario, Canada

$P$ Lebert

P Keith

$S$ Wasserman

Department of

Dermatology,

University Hospital,

Tampere, Finland

K Turjanmaa

Correspondence to

Dr Gary M Liss, Health and

Mafety Studies Unit, Ontaistry of Labour, 7th

Ministry of Labour, 7th

Floor, 400 University

Avenue, Toronto, $\mathrm{ON}$

Accepted 20 November 1996

\begin{abstract}
Objectives-To determine the prevalence of latex sensitisation among a large group of healthcare workers, study the occupational and non-occupational factors associated with latex allergy, and characterise latex exposure in air and by gloves.

Methods-All 2062 employees of a general hospital in Hamilton, Ontario, Canada who regularly used latex gloves were invited to participate in a cross sectional survey, representing the baseline phase of a prospective cohort morbidity study. Attempts were made to recruit employees who were diagnosed with latex allergy before the survey. Glove extracts were assayed for antigenic protein, and area and personal air samples were obtained on two occasions (summer and winter) to estimate exposure to airborne latex protein. A questionnaire on medical and occupational information was administered by an interviewer. Skin prick tests were performed with latex reagents, three common inhalants, and six foods.
\end{abstract}

Results-The mean (SD) latex protein concentrations were 324 (227) $\mu \mathrm{g} / \mathrm{g}$ in powdered surgical gloves and 198 (104) $\mu \mathrm{g} / \mathrm{g}$ in powdered examination gloves. Personal latex aeroallergen concentrations ranged from 5 to $616 \mathrm{ng} / \mathrm{m}^{3}$. There was a total of 1351 (66\%) participants. The prevalence of positive latex skin tests was $12 \cdot 1 \%(95 \%$ confidence interval (95\% CI) $10 \cdot 3 \%$ to $13 \cdot 9 \%$ ). This prevalence did not vary by sex, age, hospital, or smoking status but subjects who were latex positive were significantly more likely to be atopic $(P<0 \cdot 01)$. Participants who were latex positive were also significantly more likely to have positive skin tests to one or more foods (Mantel-Haenszel odds ratio (OR) adjusted for atopy $12 \cdot 1,95 \%$ CI $7 \cdot 6$ to $19 \cdot 6$, $\left.\mathbf{P}<10^{-9}\right)$. Work related symptoms were more often reported among latex positive people, and included hives (OR 6.3, 95\% CI 3.2 to $12 \cdot 5$ ), eye symptoms (OR 1.9, $95 \%$ CI 1.2 to $2 \cdot 8$ ), and wheezy or whistling chest (OR 4.7, 95\% CI 2.8 to 7.9). The prevalence of latex sensitivity was highest among laboratory workers $(16.9 \%)$, and nurses and physicians $(13 \cdot 3 \%)$. When the glove consumption per healthcare worker for each department was grouped into tertiles, the prevalence of latex skin test positivity was greater in the higher tertiles of glove use for sterile (surgical) gloves $(P<0.005)$ but not for examination gloves.

Conclusions-In this large, cross sectional study of healthcare workers, the prevalence of latex sensitisation was $12 \cdot 1 \%(9 \cdot 5 \%$ among all those eligible), and there were significant associations with atopy, positive skin tests to certain foods, work related symptoms, and departmental use of gloves per healthcare worker. This cohort is being followed up prospectively and will be retested to determine the incidence of development of latex sensitivity.

(Occup Environ Med 1997;54:335-342)

Keywords: latex; allergy; healthcare workers

Allergy to natural rubber latex has become an important occupational health concern in recent years, particularly among healthcare workers. ${ }^{1-5}$ The main source of workplace exposure is use of powdered latex gloves by healthcare workers. Workers involved in glove manufacturing may also be affected. ${ }^{6}$ Type I (IgE mediated) latex allergy includes urticaria, angioedema, rhinitis, conjunctivitis, bronchospasm, and anaphylaxis.

Surveys of healthcare workers have showed that the prevalence of sensitisation to natural rubber latex ranged from $2.9 \%$ in Finland ${ }^{7}$ to $4.7 \%$ in Belgium ${ }^{8}$ among hospital employees as a group, and from $7 \%$ among operating room staff in Finland ${ }^{7}$ to $9 \%-10 \%$ among operating room nurses in France ${ }^{9}$, and surgeons, anaesthesiologists, and radiologists in Canada. ${ }^{10}$ Vandenplas $e t a l^{8}$ documented that $2.5 \%$ of healthcare workers had occupational asthma induced by latex confirmed with specific inhalation challenge. Factors that have been associated with latex allergy in previous studies of healthcare workers include atopy, skin rash (mainly hand dermatitis), and occupation. Relations with measures of cumulative exposure or hours of glove use have not been convincing. ${ }^{7811} \mathrm{~A}$ recent Finnish study, however, found skin symptoms among hospital workers associated with hours of daily glove use but tests for latex allergy were not performed. ${ }^{12}$

It is postulated that exposure to medical gloves high in latex protein has sensitised many healthcare workers. Sensitisation of these workers may involve high costs, both in terms of day to day risks at work, as well as potentially fatal anaphylactic shock. Disability 
from latex sensitivity is an increasing problem requiring substitution of latex products, personnel reassignments, and workers' compensation claims. Turjanmaa and Lahti ${ }^{13}$ found that people already sensitised to latex reacted less to an extract taken from a low protein glove than to an extract from a regular glove. Also, Vandenplas et al ${ }^{14}$ suggested that gloves with a lower protein content could be useful in reducing the risk of asthmatic reactions in subjects with latex induced asthma. It is not known, however, if the use of low protein gloves will reduce the incidence of latex sensitisation. The need for such a study has been noted. ${ }^{515}$

During 1992 and 1993, many healthcare workers at a hospital (with two sites) in Hamilton, Ontario, Canada, developed allergic symptoms that were associated with exposure to latex. This provided an opportunity to undertake the current investigation to test the hypothesis that high protein concentrations in latex gloves are related to the incidence of sensitisation. The objectives of this study were to examine (a) the prevalence of latex allergy in a group of healthcare workers, $(b)$ the factors associated with latex allergy at baseline, $(c)$ the incidence in the prospective phase, at which people within this group become newly sensitised to latex, and (d) the association, if any, between the rate of sensitisation and the protein content of the latex gloves worn or airborne exposure.

\section{Overall design}

The study design had two main components. The first phase was a cross sectional investigation in which healthcare workers who used latex gloves at the two sites of the Hamilton hospital were screened to find the baseline prevalence of sensitivity to latex. The second component involved prospectively following up the cohort, and retesting after one year to identify changes in latex sensitivity and newly sensitised people (objectives $c$ and $d$ ). At one site, most departments continued to use the same powdered gloves as in the past, whereas at the other site, powderless low protein gloves were introduced. In this report, we describe the prevalence findings at baseline among the participants.

\section{Methods}

\section{ELGIBLE POPULATION}

All 2062 employees at both sites who used latex gloves on a regular basis (at least once or twice a week) were invited to participate in the baseline screening. The assessment included administration of a questionnaire, latex skin testing, and obtaining serum samples. The results of in vitro assays of serum samples for IgE antibody to latex will be reported separately. Informed signed consent was obtained from all participants and the study protocol received approval from the review board of the hospital.

To promote participation, advanced publicity included meetings with union leaders; notice in the hospital newsletters; and presentations to large hospital groups. Testing and interviewing occurred over four weeks. Those employees who had been documented as having latex allergy during the two years before the study were encouraged to participate. These employees were also identified by affirmative answers from the questionnaire to the questions "Have you ever been told by a doctor that you have an allergy to latex?" and "Was the doctor's statement based on a skin prick test for latex allergy?" Those employees who completed a questionnaire and answered affirmatively were included in the study analysis and were considered to be latex positive. (In fact, all those who were retested by an allergist were clearly positive to the latex skin prick test.) All 76 people known to be sensitised (whether participants in the questionnaire or not) are included in the overall estimate of prevalence.

\section{QUESTIONNAIRE}

The questionnaire was given by four trained interviewers. It obtained information on occupational history including job title, department, number of pairs of gloves, and number of hours of gloves used (over the three days before interview), types of glove worn during past year, glove brands, exposure to other latex items (household cleaning gloves, balloons, diaphragm, latex condoms), number of times a day that hands were washed, and exposure to chemical irritants at work. We also asked about smoking, medical history, and allergies. Questions about symptoms were adapted from a questionnaire previously used in health hazard evaluations in Ontario and at the National Institute for Occupational Safety and Health (NIOSH). ${ }^{1617}$

\section{DEFINITIONS OF SYMPTOMS}

The questionnaire asked whether the following symptoms were present "on a persistent basis". Skin rash (dermatitis or hives) was considered to be present if reported a few times a month or all the time. Eye symptoms were present if two or more symptoms (burning, running, or itching) were reported and the frequency was at least a few days a week. Mouth irritation symptoms were present if one or more symptoms (itchy throat, tongue, or roof of the mouth) were reported at least a few days a week. Nasal symptoms were considered to be present if two or more symptoms (sneezing, runny, stuffy, or itchy nose) were reported at least a few days a week. A persistent cough was present if the frequency was at least a few days a week. Wheezy or whistling chest was present if it occurred "occasionally even when you don't have a cold" or "most days or nights". Each of these symptoms (except for rash) was considered to be work related if the symptom met the above conditions and if it occurred not at all or less often on days away from work or when on holiday compared with workdays. It was not considered realistic that a rash would necessarily subside over a weekend. Associations of positive skin prick test to latex with symptoms were adjusted for atopy. 
SKIN TEST DEFINITIONS

A positive skin prick test was defined as a wheal diameter of at least $4 \mathrm{~mm}$. Atopy was defined as two or more positive skin prick tests to common inhalant aeroallergens (ragweed, dust mite, or timothy grass). A positive latex skin prick test was defined as a positive skin test to any of the latex reagents tested.

\section{LATEX SKIN TEST REAGENTS}

Skin testing was done with dilutions of commercially available ammoniated latex extracts (Bencard Laboratory, Mississauga, Ontario, Canada). Bencard latex extracts were analysed in vitro by the western blotting technique and contained all relevant proteins. ${ }^{18}$ Skin test dilutions to $1: 10,1: 100,1: 1000,1: 10000$, 1:100 000 , and 1:1 000000 of the stock latex extracts were prepared with saline diluent. In patients with histories suggestive of latex allergy (identified by questionnaire), skin tests were carried out beginning with the lowest dilution and progressing through increasing concentrations until a definite positive skin test was obtained. In patients with no symptoms suggestive of latex allergy, skin tests were carried out with all latex dilutions at one time.

Another reagent containing latex proteins was extracted from non-compounded ammoniated latex. Three lots of ammoniated latex (Guthrie Latex) were mixed together and poured on to a large glass plate. The latex was air dried overnight to produce a thin sheet. The resulting latex film was cut into small pieces, placed in polyethylene bottles, and extracted with continuous agitation in $0.05 \mathrm{M}$ carbonate buffer pH 9.6 , overnight at $37^{\circ} \mathrm{C}$. The extract was collected, centrifuged $(2000 \mathrm{~g})$, and dialysed (MWCO 1000) against $\mathrm{H}_{2} \mathrm{O}$ for two days at $4^{\circ} \mathrm{C}$ and lyophilised. The residue was reconstituted to $1 \mathrm{mg} / \mathrm{ml}$ in sterile $0.05 \mathrm{M}$ carbonate buffer ( $\mathrm{pH} \mathrm{9.6)}$ containing $30 \%$ glycerol.

Glove extracts used for skin testing were prepared as reported previously. ${ }^{19}$ Two grams of the palmar surface of latex rubber gloves (Suretex (Page Products, Burlington, Ontario); Microtouch (Johnson and Johnson, Arlington, Texas); No-Powder (Ansell Medical, Eatontown, New Jersey); Neutraderm (Aladan Corporation, Dothan, Alabama)) were cut into $2 \mathrm{~cm}$ squares and submerged in $10 \mathrm{ml}$ saline, agitated for $30 \mathrm{sec}-$ onds to ensure all parts were wetted, and left for 15 minutes. The latex extracts were prepared in polypropylene tubes and containers. The final latex glove extracts were refrigerated and stored in $5 \mathrm{ml}$ aliquots. The solution was labelled with date, glove brand, and glove lot number. The extract was assayed for antigenic protein with an indirect enzyme linked immunosorbent assay (ELISA) technique. ${ }^{20}$

FOOD AND INHALANT SKIN TEST EXTRACTS Commercially available food and inhalant extracts were used for skin testing. Food extracts (Bencard Laboratory, Mississauga, Ontario) included avocado, banana, kiwi, potato (all 1:10 dilution), and chestnut and cow's milk (1:20 dilution). Inhalant extracts included ragweed, Timothy grass, dust mite (Bencard Laboratory, Mississauga, Ontario, Canada). Histamine (1:1000) (Bencard Laboratory), and physiological saline served as positive and negative controls, respectively.

\section{SKIN TEST METHOD}

Skin prick tests were performed by trained registered nurses. Both forearms were wiped clean with alcohol. Skin test sites were clearly marked, a drop of extract was placed on the skin, and this was pricked with commercially available skin test lancets (Hollister Stier Laboratory, Etobicoke, Ontario, Canada). Skin tests were read at 15 minutes; all positive tests were measured. All positive skin test wheal and flare responses were outlined with black pen and transferred to paper with transparent tape. Those tests that were $\leqslant 3 \mathrm{~mm}$ were considered negative. Forty seven subjects with latex minus saline differences of $3 \mathrm{~mm}$ were considered equivocal and referred to an allergist for follow up tests; 27 of these were seen and tested and the allergist's skin test diagnosis was used in the analysis. Subjects with $3 \mathrm{~mm}$ wheal responses who did not attend were considered negative.

\section{OUTCOMES EXAMINED AT BASELINE}

We declared in advance our interest in examining the prevalence of positive skin prick tests to latex, occupational and non-occupational factors that might predict latex skin prick test status, and whether work related symptoms were associated with latex skin prick test status.

\section{EXPOSURE ASSESSMENT \\ Direct exposure}

To provide estimates of the range of airborne latex concentrations, a few area and personal air samples were obtained in both hospitals to characterise areas of frequent and no or low glove use. These were conducted on two occasions (winter and summer) to reflect different ventilation conditions. In this report we describe the results from areas in which powdered (moderate protein) gloves were used, which reflected exposures during the exposure induction period before this prevalence survey. The results of sampling at places where powderless low protein gloves were used will be communicated in the report of the follow up study.

\section{Air sampling method}

Air samples assayed for airborne latex protein were collected by drawing air through teflon (polytetrafluoroethylene) filters at a flow rate of 3.5 or $4.0 \mathrm{l} / \mathrm{min}$ for personal samples and $180 \mathrm{l} / \mathrm{min}$ for area samples.

\section{Analytical method}

The immunoassay for latex aeroallergens has been previously described. ${ }^{21} 22$ Briefly, the latex allergens were extracted with buffer and measured by inhibition immunoassay with a concentrated extract from latex gloves adsorbed on to plastic microtitre plates and IgE antibodies specific to latex pooled from five latex sen- 
Table 1 Results of air sampling for latex: Hamilton Hospitals Latex Study, Ontario, 1994

\begin{tabular}{|c|c|c|c|c|}
\hline \multirow[b]{2}{*}{ Hospital (location) } & \multicolumn{2}{|c|}{ Personal samples $\left(\mathrm{ng} / \mathrm{m}^{3}\right)$} & \multicolumn{2}{|c|}{ Area samples $\left(\mathrm{ng} / \mathrm{m}^{3}\right)$} \\
\hline & Summer 1994 & Winter 1995 & Summer 1994 & Winter 1995 \\
\hline Wards & $\begin{array}{r}5 \\
9 \\
19 \\
37 \\
83\end{array}$ & $\begin{array}{r}40 \\
87 \\
388 \\
616\end{array}$ & $\begin{array}{l}4 \\
6\end{array}$ & $\begin{array}{l}20 \\
24\end{array}$ \\
\hline Operating rooms & $\begin{array}{l}7 \\
7\end{array}$ & 133 & $\begin{array}{r}5 \\
19\end{array}$ & $\begin{array}{l}29 \\
33\end{array}$ \\
\hline
\end{tabular}

Table 2 Comparison of study participants with those eligible: Hamilton Hospitals Latex Study, Ontario, 1994

\begin{tabular}{lcc}
\hline & $\begin{array}{l}\text { Participants } \\
(n=1351) \\
n(\%)\end{array}$ & $\begin{array}{l}\text { Eligible } \\
(n=2062) \\
n(\%)\end{array}$ \\
\hline Year of birth (known for 1305): & & \\
$<1940$ & $80(6 \cdot 1)$ & $128(6 \cdot 2)$ \\
$1940-49$ & $284(21 \cdot 8)$ & $412(20 \cdot 0)$ \\
$\quad 1950-59$ & $407(31 \cdot 2)$ & $657(31 \cdot 9)$ \\
$\geqslant 1960$ & $534(40 \cdot 9)$ & $865(41 \cdot 9)$ \\
Sex (F, n (\%)) & $1208(91 \cdot 1)$ & $1916(92 \cdot 9)$ \\
Hospital site (known for 1296) (n (\%)): & $753(58 \cdot 1)$ & $1212(58 \cdot 8)$ \\
$\quad$ General & $543(41 \cdot 9)$ & $850(41 \cdot 2)$ \\
Henderson & & \\
\hline
\end{tabular}

sitive people. The results were expressed as latex allergenic protein $/ \mathrm{m}^{3}$ air. The lower analytical limit of detection of this method was about $2 \mathrm{ng}$ or $40 \mathrm{ng} / \mathrm{ml}$.

\section{Indirect exposure measures}

It was not feasible to sample all wards or areas. The following extra variables were declared in advance to be exposure metrics of interest to explore as possible predictors of a positive skin prick test to latex: hospital; departmental use of gloves (obtained from hospital purchasing records over the previous year); job title; number of gloves a day averaged over the three days before the interview; number of hours a day wearing gloves; and exposure to chemical irritants at work.

\section{STATISTICAL ANALYSES}

We compared categorical variables with $\chi^{2}$ tests or Fisher's exact test (two tailed) and continuous variables with $t$ tests as appropriate. The association of work related symptoms

Table 3 Characteristics of participants positive for skin prick test (SPT) to latex: Hamilton Hospitals Latex Study, Ontario, 1994

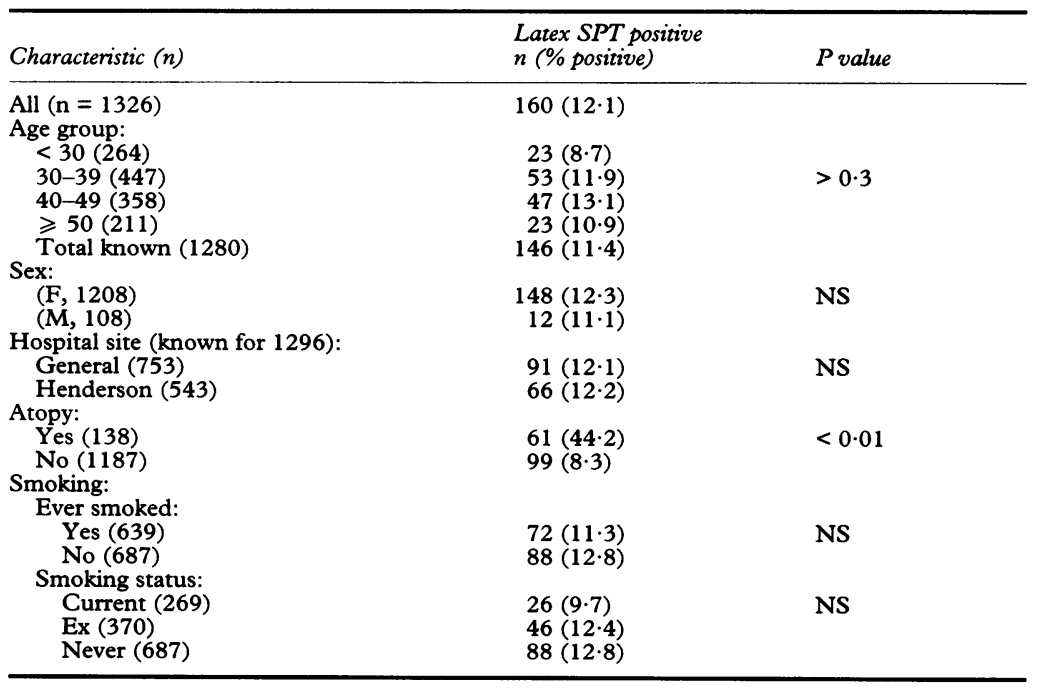

among skin prick test positive and negative subjects was compared after adjustment for atopy with Mantel-Haenszel odds ratios (ORs). In these analyses, the probability of homogeneity across strata of the variable, atopy, was calculated as an indicator of possible interaction. The ORs for chest symptoms were also adjusted for smoking. For the comparisons of glove use between groups, we used the Mann-Whitney test. We used the SAS (Cary, NC), SPSS (Chicago, Ill), Epistat (Epistat Services, Richardson, Texas), and SYSTAT (Chicago, Ill) statistical programs. A P value of $<0.05$ was considered to be significant.

\section{Results}

EXPOSURE

The powdered surgical gloves used were found to have mean (SD) latex protein concentrations of 324 (227) $\mu \mathrm{g} / \mathrm{g}$ (for 45 lots) and the powdered examination gloves had 198 (104) $\mu \mathrm{g} / \mathrm{g}$ (for six lots) with the ELISA method. The protein concentrations were measured for representative lot numbers used from March to September 1994. Table 1 displays the results of personal and area sampling for airborne latex during use of regular powdered gloves. All samples where gloves were not in use showed non-detectable concentrations. The personal exposures ranged from $5-83 \mathrm{ng} / \mathrm{m}^{3}$ in the summer, and 40 to $616 \mathrm{ng} / \mathrm{m}^{3}$ in the winter. The number of pairs of powdered gloves reported as used on the days of sampling ranged from three to 14 (median six). When we examined the correlation between the number of pairs of gloves, and the personal latex exposures of employees sampled on the wards, there was no positive correlation overall $(r=-0 \cdot 26, \quad \mathrm{n}=9)$. However, when analysed according to season, there was a moderate negative correlation in the summer, when exposures were lower $(r=$ $-0 \cdot 6, n=5)$, but a weak positive correlation in the winter, when exposures were much higher $(r=0.3, \mathrm{n}=4)$. After excluding the highest outlying value of $616 \mathrm{ng} / \mathrm{m}^{3}$, there was a moderately strong positive correlation in winter $(r=0 \cdot 6, \mathrm{n}=3)$.

PARTICIPANTS

The total number of participants in the baseline survey was 1351 , representing a participation rate of $66 \%$. The participants included 40 $(53 \%)$ of the 76 employees identified as sensitive to latex before the survey. Participation was voluntary; thus, it was not possible to contact non-participants for reasons for not participating. However, compared with all those eligible to participate, the participants were identical for age, sex, and hospital (table 2).

PREVALENCE OF POSITIVE SKIN PRICK TESTS TO LATEX

Among the 1326 participants with skin tests, there were $160(12 \cdot 1 \%)$ who were positive to latex (95\% confidence interval (95\% CI) $10.3 \%$ to $13.9 \%$ ). Including all those previously known to be latex positive, an estimate of the minimum prevalence in the entire eligible 
Table 4 Frequency of positive skin tests to latex reagents: Hamilton Hospitals Latex Study, Ontario, 1994

\begin{tabular}{ll}
\hline Reagent & $\begin{array}{l}\text { Skin prick test } \\
\text { positive }(n)\end{array}$ \\
\hline Bencard full $(7 \cdot 5 \mathrm{mg} / \mathrm{ml})$ & 56 \\
Bencard $1: 10$ & 37 \\
Bencard $1: 100$ & 10 \\
Bencard $1: 1000$ & 2 \\
Bencard $1: 10000$ & 0 \\
Bencard $1: 100000$ & 0 \\
Bencard $1: 1000000$ & 1 \\
Ammoniated latex $(1 \mathrm{mg} / \mathrm{ml})$ & 37 \\
\hline
\end{tabular}

population was $9 \cdot 5 \% \quad(95 \%$ CI $8 \cdot 2 \%$ to $10 \cdot 8 \%$ ). All subsequent analyses refer to the survey participants only. Table 3 shows the demographic and background characteristics of the people positive and negative for skin prick tests to latex. The prevalence of positivity did not vary by sex, hospital, or smoking. There was also no significant difference in age distribution, although the prevalence of positivity was somewhat lower in the youngest group. Subjects who were sensitive to latex were significantly more likely to be atopic than those who were negative (table 3); atopy was considered in subsequent analyses. Overall, $10.4 \%$ of participants were atopic. Table 4 shows the relative frequency with which the latex skin test reagents elicited positive responses.

We examined other potential sources of exposure to latex. The prevalence of reported past surgical or radiological procedures, or adverse reactions during such procedures did not differ between those who were positive and those who were negative for skin prick tests to latex. We also asked about exposure to condoms, balloons, and household cleaning gloves in the past month; however, fewer than $20 \%$ of participants responded to this question. Of those responding, those who were latex positive were somewhat less likely to report exposure to balloons $(31 \cdot 8 \% v 46 \cdot 8 \%)$ and household gloves (34.6 $v 46.9 \%)$ but were as likely to report use of latex condoms in the past month $(9 \cdot 5 \% v 9 \cdot 6 \%)$.

\section{ASSOCIATION OF FOOD ALLERGY AND LATEX SKIN PRICK TEST STATUS}

Participants who were positive for skin prick tests to latex were much more likely to have positive skin tests to one or more of the tested foods $(71(44.4 \%)$ of 160$)$ than those who were skin test negative $(49(4 \cdot 2 \%)$ of $1166, \mathrm{P}<$ $0.001)$; this association was found among people with atopy (OR 10.5) and without (OR $12 \cdot 9$, Mantel-Haenszel OR adjusted for atopy $12 \cdot 2,95 \%$ CI $7 \cdot 6$ to $\left.19 \cdot 6, \mathrm{P}<10^{-9}\right)$. The detailed findings for specific foods will be reported separately.

\section{SYMPTOMS ACCORDING TO LATEX SKIN PRICK}

TEST STATUS

Table 5 shows the association of work related symptoms with skin prick tests to latex. All symptoms were more prevalent among people positive than negative for skin prick tests to latex, with little change in relative risk after adjustment for atopy. The associations were strongest for hives and for wheezy or whistling chest, and were significant for these symptoms as well as for itchy skin, skin rash, and eye symptoms. For cough and mouth irritation, the associations were also positive but the $95 \%$ CIs for the ORs included unity. The ORs for respiratory conditions (cough, and wheezy or whistling chest) did not change when they were further adjusted for smoking (table 5). In general, the associations with positive skin prick tests to latex were stronger among people without than with atopy for almost all symptoms (table 5). For nasal symptoms there was a significant interaction with atopy.

Table 5 Prevalence of work related symptoms according to latex skin test status: Hamilton Hospitals Latex Study, Ontario, 1994

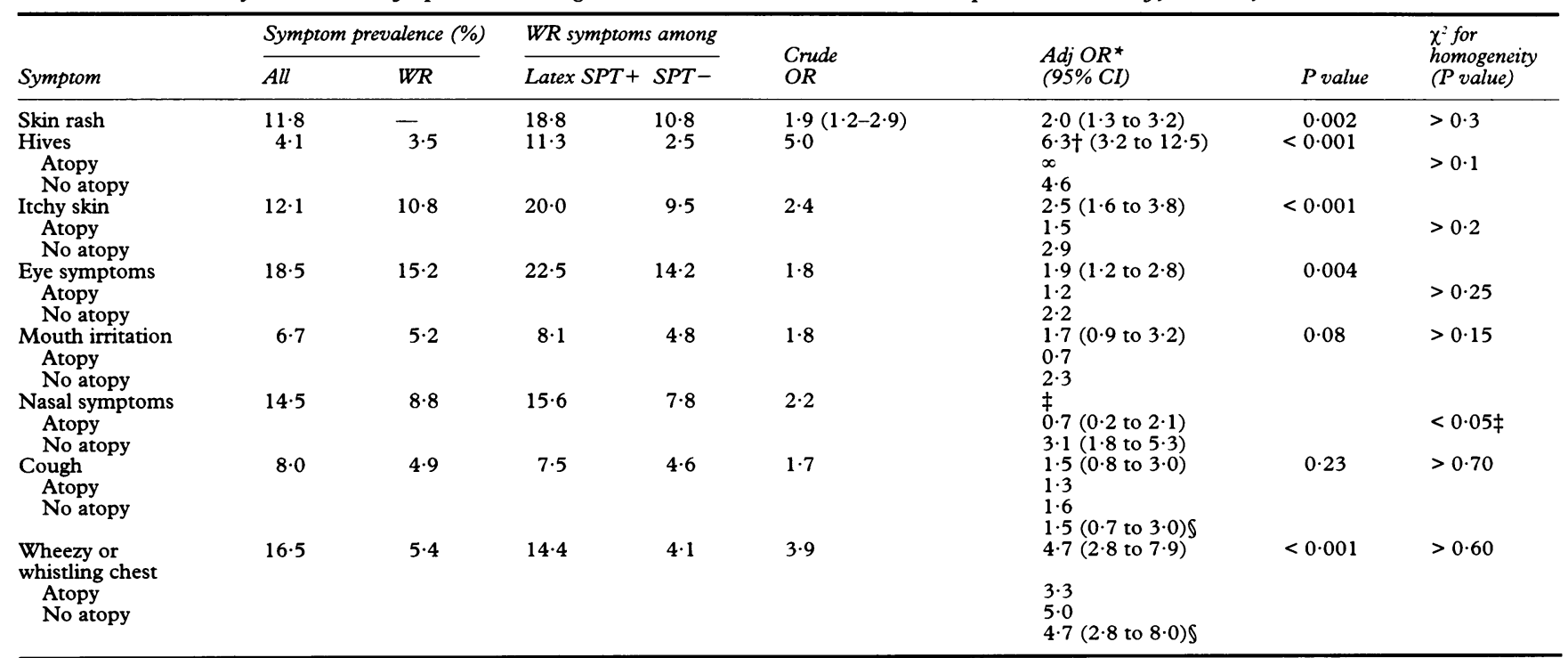

*Mantel-Haenszel OR for association of symptoms and latex SPT status, adjusted for atopy status. 
Table 6 Comparison of various exposure measures between latex skin prick test (SPT) + and SPT - participants: Hamilton Hospitals Latex Study, Ontario, 1994

\begin{tabular}{|c|c|c|c|}
\hline Exposure measure & Latex $S P T+$ & latex $S P T-$ & $P$ value ${ }^{*}$ \\
\hline \multicolumn{4}{|l|}{ Job title $(\%)$ : } \\
\hline Lab workers $(65)$ & 16.9 & $83 \cdot 1$ & \multirow{5}{*}{$0 \cdot 15$} \\
\hline Nurses and physicians (788) & $13 \cdot 3$ & $86 \cdot 1$ & \\
\hline Housekeepers (78) & 11.5 & 88.5 & \\
\hline Therapists and technicians (145) & $7 \cdot 6$ & $92 \cdot 4$ & \\
\hline Others $(231)$ & $9 \cdot 5$ & 90.5 & \\
\hline \multirow{2}{*}{\multicolumn{3}{|c|}{$\begin{array}{l}\text { Gloves per day (mean (SD) over past } \\
3 \text { days): }\end{array}$}} & Mann- \\
\hline & & & Whitney \\
\hline Total & $9 \cdot 4(12 \cdot 3)$ & $9 \cdot 5(12 \cdot 5)$ & $>0.7$ \\
\hline Latex & $5 \cdot 4(10 \cdot 1)$ & $6 \cdot 6(11 \cdot 6)$ & 0.04 \\
\hline Vinyl & $4 \cdot 0(8 \cdot 7)$ & $2 \cdot 9(7 \cdot 1)$ & 0.03 \\
\hline \multicolumn{4}{|l|}{ Hand contact ( $\% \geqslant 1 /$ week) with: } \\
\hline Formaldehyde & $3 \cdot 1$ & $3 \cdot 1$ & $>0.9$ \\
\hline Glutaraldehyde & $1 \cdot 3$ & $2 \cdot 3$ & $>0.3$ \\
\hline Bleaches & $11 \cdot 3$ & $16 \cdot 6$ & 0.08 \\
\hline Cleaners & 22.5 & $22 \cdot 4$ & $>0.9$ \\
\hline
\end{tabular}

EXPOSURE FACTORS ACCORDING TO LATEX SKIN PRICK TEST STATUS

Irritants

Those who were latex positive were somewhat less likely to have had hand contact with bleaches or glutaraldehyde and were as likely to have been exposed to formaldehyde or hand contact with cleaners (table 6). There was no association of skin prick test positivity with the number of times a day that the participants washed their hands at work or use of hand cleaners before donning gloves.

\section{Fob title}

The prevalence of latex positivity was highest among nurses, physicians, and laboratory workers and intermediate among housekeepers; however, the differences between job categories were not significant (table 6).

USE OF GLOVES BY HEALTHCARE WORKERS

Over the three days before the survey, there were no differences between those who were and were not allergic to latex in the total number of pairs of gloves used each day (table 6) or hours that latex gloves were worn each day (data not shown). However, those who were latex positive reported using fewer latex and more vinyl gloves a day than those who were not (table 6).

\section{Glove consumption by departments}

For use of sterile gloves and bulk (examination) gloves, the consumption per healthcare worker by department was ranked and grouped into tertiles. For each department, the proportion of participants who were positive for skin prick tests to latex was found and categorised into whether this prevalence for positivity was higher or lower than the overall prevalence. For use of sterile gloves, there was

Table 7 Prevalence of positive skin prick tests (SPT) to latex and departmental glove consumption

\begin{tabular}{|c|c|c|}
\hline $\begin{array}{l}\text { Latex glove consumption/ } \\
\text { healthcare worker }\end{array}$ & $\begin{array}{l}\text { Departments with } S P T \\
\text { prevalence exceeding } \\
\text { overall average }(n)\end{array}$ & $\chi^{2}$ test \\
\hline \multicolumn{3}{|l|}{ Sterile gloves: } \\
\hline Lowest tertile departments & $\begin{array}{l}1 \text { of } 10 \\
9 \text { of } 10\end{array}$ & $\begin{array}{l}15 \cdot 8 \\
(2 \mathrm{df} ;\end{array}$ \\
\hline \multicolumn{3}{|l|}{ Bulk (examination) gloves: } \\
\hline $\begin{array}{l}\text { Lowest tertile departments } \\
\text { Medium tertile departments } \\
\text { Highest tertile departments }\end{array}$ & $\begin{array}{l}6 \text { of } 13 \\
5 \text { of } 13 \\
8 \text { of } 13\end{array}$ & $\begin{array}{l}1 \cdot 44 \\
(2 \mathrm{df} \\
P>0 \cdot 20)\end{array}$ \\
\hline
\end{tabular}

evidence that in departments with high glove consumption per healthcare worker there was a high prevalence of positive skin prick tests to latex (table 7). However, this relation could not be found for examination gloves.

\section{Discussion}

In this study, which is one of the largest cross sectional surveys undertaken for latex sensitivity among healthcare workers, the estimate of the prevalence of latex positivity among participants was $12 \cdot 1 \%$ (and an estimate of the minimum prevalence in the total eligible population was $9.5 \%$ ), comparable with the upper range of previous estimates. ${ }^{9}{ }^{10}$ Because we used a relatively conservative definition of positive latex sensitivity (at least $4 \mathrm{~mm}$ diameter wheal), it is unlikely that the prevalence has been greatly overestimated. For comparison, the prevalence of latex allergy in the general population is thought to be less than $1 \% .^{7}$

Although only a portion of those with immunological sensitisation were symptomatic or were likely to have had occupational asthma, this prevalence of allergic sensitisation constitutes a high "attack rate" or proportion affected. Our finding of the strong association with atopy is consistent with previous findings. ${ }^{781123}$ At least $40 \%$ of participants with positive skin prick tests to latex were asymptomatic; the clinical significance of asymptomatic positivity is not known but this may identify a group at risk of becoming symptomatic in the future. Prospective follow up will be required to answer this question.

There was little evidence that those who were latex positive had more frequent exposure to other sources of latex exposure such as past operations, condoms, or household gloves. However, these findings should be interpreted with caution due to the small numbers responding and because this reflects only the month before the survey. It is possible that respondents modified these practices after becoming sensitised.

The most likely source of latex exposure was from the use of gloves at work. The air sampling results documented exposure to latex during use of gloves with no exposure detectable in the background areas where gloves were not used. The concentrations were higher in the winter and were comparable with the range of 39 to $311 \mathrm{ng} / \mathrm{m}^{3}$ documented in a laboratory setting ${ }^{22}$ and $8 \mathrm{ng} / \mathrm{m}^{3}$ to $974 \mathrm{ng} / \mathrm{m}^{3}$ in the breathing zone of healthcare workers who used powdered gloves. ${ }^{21}$ We found limited evidence of a positive correlation between the number of pairs of powdered gloves used and personal latex exposure during the winter, when there was decreased circulation of fresh air and exposure was higher. Heilman et al ${ }^{24}$ recently found a similar correlation of latex aeroallergen concentrations with the number of latex gloves containing high concentrations of allergen $(r=0.66)$, based on many more observations.

A possible mechanism leading to sensitisation other than through inhalation could involve exposure to irritants-for example, 
bleaches and cleaners - causing impairment of the integrity of the skin barrier, allowing entry of latex antigen. For example, Turjanmaa ${ }^{7}$ found skin irritation from gloves and hand eczema to be more frequent among those positive to skin tests, as did Charous et al. ${ }^{11}$ Our subjects positive for skin prick tests to latex did not report more frequent hand contact to irritants such as bleach and cleaners but did report a greater prevalence of skin rashes. It is possible that this may reflect that those who were sensitised (and previously had contact) were now avoiding these materials.

\section{REACTIONS TO FOODS}

Our finding of a very strong association of reaction to foods such as chestnut, banana, and kiwi, with latex positivity confirms previous reports by us ${ }^{25}$ and by others. ${ }^{26}$

\section{SYMPTOMS}

The prevalence of most work related symptoms was found to be relatively low (usually below $10 \%$ ). However, all symptoms were positively associated with being latex positive-that is, they were reported more often by those who were sensitised to latex. This association was strongest for hives (as opposed to symptoms of the eye, mouth, nose, and chest), which more specifically indicates a condition related to latex mediated through $\mathrm{IgE}$. The association of symptoms and latex skin prick test status was generally stronger among people without rather than with atopy. The explanation for this is not known but it may be that people with atopy have higher background symptoms or react to non-specific triggers more often than those without, and therefore, it may be more difficult to detect a further increase after sensitisation to latex. However, in our data, symptoms were remarkably similar among those with and without atopy (data not shown). Alternatively, people without atopy may not respond to non-specific irritants in the workplace but may develop symptoms when sensitised and then exposed.

For nasal symptoms, there was a significant interaction between results of skin prick tests to latex and atopy, with the direction of the association differing according to atopic status. For respiratory symptoms, cough was not significantly associated with skin prick test results but wheezy or whistling chest was. This symptom is more closely identified with bronchospasm but as the final clinical diagnosis is not known in all cases, it is not possible to speculate about the interpretation.

\section{EXPOSURE VARIABLES}

Previous studies have shown associations between the prevalence of latex sensitivity and job title, but few have been able to show relations with other factors related to exposure. Kujala and Reijula ${ }^{12}$ found that in a logistic regression analysis, skin symptoms among 522 hospital workers in Finland were associated with hours of daily use of gloves and work experience (decreasing with years worked). Interestingly, there was no association between glove type (latex $v$ vinyl) and skin symptoms when other factors were taken into account in the model, but latex sensitivity was not ascertained.

We found that the prevalence of positive skin prick tests to latex was greater (although not significantly so) among physicians, nurses, and laboratory workers. The prevalence was intermediate among housekeepers, consistent with our recent findings at a Toronto hospital. ${ }^{23}$ We failed to find an association with the number of hours that gloves were worn each day, although those who were latex positive reported using fewer latex gloves a day. However, because the participants were asked about the three days before the survey, this may not reflect past use of gloves in the relevant period when sensitisation occurred. In fact, some participants who were sensitised may have already modified their practice to reduce their use of latex gloves.

The positive association that we found with glove use per healthcare worker is interesting and needs to be confirmed elsewhere. Because this measure represents a measure of exposure through gloves by department over the past year (and may reflect use of gloves in earlier periods as well), it may relate more meaningfully to the period of sensitisation. This relation was found for sterile but not for bulk gloves. Whether this is due to a difference between sterile and bulk gloves (the mean latex protein concentration was $50 \%$ higher in the sterile gloves), to a difference in the activities conducted with sterile gloves, to misclassification of use of bulk gloves, or to other factors is not clear.

\section{LIMITATIONS}

This study was limited in part by its cross sectional design. Subjects who may have developed latex sensitivity may have left the workforce before the study, leading to an underestimation of the prevalence of latex sensitivity. This was considered in part by offering those previously diagnosed an opportunity to participate, and successfully recruiting a high proportion of them. Also, we included all those previously diagnosed in the estimate of the minimum prevalence. Selection bias was also possible if non-participants differed somehow from participants or if those who thought that they were symptomatic or sensitised to latex were more likely to participate, which could result in an overestimation of risk estimates. Although we were unable to interview non-participants, table 2 suggests that the groups were essentially identical in several key characteristics. Finally, it should be acknowledged that no gold standard or controlled challenge was used in this study for confirming clinical sensitivity.

\section{SUMMARY}

The best estimate for the prevalence of positive skin prick tests to latex among participants in this large cross sectional study was about $12 \%$. Strong associations were found between latex positivity and atopy, positive skin tests to foods, and work related symptoms. Occupational risk factors of positive skin prick tests 
to latex included job title and an interesting association with use of sterile gloves per healthcare worker within departments. The workers in this study will be followed up prospectively and retested to determine the incidence of development of sensitivity to latex.

This work was supported in part by Aladan Corporation (Dothan, Alabama), Ansell Medical (Eatontown, New Jersey), and Regent Hospital Products (Greenville, South Carolina) The cooperation of these companies and Johnson and Johnson (Arlington, Texas), and Page Products (Burlington, Ontario) is appreciated.

We thank the participants themselves and the hospital administration. Marlene Vaz assisted with preparation of the tables.

1 Sussman GL, Beezhold DM. Allergy to latex rubber [editorial]. Ann Intern Med 1995;122:43-6.

2 Slater JE. Latex allergy. F Allergy Clin Immunol 1994;94: $139-49$.

3 Sussman GL, Tarlo S, Dolovich J. The spectrum of IgEmediated responses to latex. $7 A M A$ 1991;265:2844-7.

4 Charous BL. The puzzle of latex allergy: some answers, stil more questions [editorial]. Ann Allergy 1994;73:277-81.

5 Hunt LW, Fransway AF, Reed CE, Miller LK, Jones RT, Swanson MC, et al. An epidemic of occupational allergy to Swanson MC, et al. An epidemic of occupational allergy to latex involving heal

6 Tarlo SM, Wong L, Roos J, Booth N. Occupational asthma caused by latex in a surgical glove manufacturing plant. $\mathcal{F}$ Allergy Clin Immunol 1990;85:626-31.

7 Turjanmaa $\mathrm{K}$. Incidence of immediate allergy to latex gloves in hospital personnel. Contact Dermatitis 1987;17: $270-5$.

8 Vandenplas O, Delwiche J-P, Evrard G, Aimont P, Van der Brempt X, Jamart J, Delaunois L. Prevalence of occupational asthma due to latex among hospital personnel. Am f Respir Crit Care Med 1995;151:54-60.

9 Lagier F, Vervloet D, Lhermet I, Poyen D, Charpin D. Prevalence of latex allergy in operating room nurses. $\mathcal{f}$ Allergy Clin Immunol 1992;319:319-22.

10 Arellano R, Bradley J, Sussman G. Prevalence of latex sensitization among hospital physicians occupationally exposed to latex gloves. Anesthesiology 1992;77:905-8.

11 Charous BL, Hamilton RG, Yunginger JW. Occupational latex exposure: characteristics of contact and systemic reactions in 47 workers. 7 Allergy Clin Immunol 1994:94: $12-18$

12 Kujala VM, Reijula KE. Glove-induced dermal and respiratory symptoms among health care workers in on Finnish hospital. Am ₹ Ind Med 1995;28:89-98

13 Turjanmaa K, Lahti A. Prick and use tests with 6 glove brands in patients with immediate allergy to rubber proteins. Contact Dermatitis 1992;26:259-62.

14 Vandenplas O, Delwiche J-P, Depelchin S, Sibille Y, Vande Weyer R, Delaunois L. Latex gloves with a lower protein content reduce bronchial reactions in subjects with occupational asthma caused by latex. Am $\mathcal{f}$ Respir Crit Care Med 1995;151:887-91.

15 Hamann CP. Natural rubber latex protein sensitivity in review. Am f Contact Derm 1993;4:4-21.

16 Liss GM, Bernstein D, Genesove L, Roos JO, Lim J. Assessment of risk factors for IgE-mediated sensitization to tetrachlorophthalic anhydride. $\mathcal{F}$ Allergy Clin Immuno 1993;92:237-47.

17 Smith BA, Bernstein DI, Aw TC, Gallagher JS, London M Kopp S, Carson GA. Occupational asthma from inhaled egg protein. Am f Ind Med 1987;12:205-18.

18 Beezhold DH, Chang N-S, Kostyal DA, Sussman GL Identification of a 46 kilodalton latex protein allergen in healthcare workers. Clin Exp Immunol 1994;98:408-13.

19 Turjanmaa K. Contact urticaria from latex gloves. In: Mellstrom GA, Wahlberg JE, Maibach HI, eds. Protective gloves for occupational use. Boca Raton, Florida: CRC gloves for occupational

20 Beezhold D. LEAP: latex ELISA for antigenic protein. Guthrie fournal 1992;61:77-81.

21 Swanson MC, Bubak ME, Hunt LW, Yunginger JW Warner MA, Reed CE. Quantification of occupational latex aeroallergens in a medical center. $\mathcal{F}$ Allergy Clin Immunol 1994;94:445-51.

22 Tarlo SM, Sussman G, Contala A, Swanson MC. Control of airborne latex by use of powder-free latex gloves. Allergy Clin Immunol 1994;93:985-9.

23 Sussman GL, Lem D, Liss GM, Beezhold D. Latex allergy in housekeeping personnel. Ann Allergy 1995;74:415-8.

24 Heilman DK, Jones RT, Swanson MC, Yunginger JW. A prospective, controlled study showing that rubber gloves are the major contributor to latex aeroallergen levels in the operating room. $f$ Allergy Clin Immunol 1996;98: 325-30.

25 Beezhold DH, Sussman GL, Liss GM, Chang N-S. Latex allergy can induce clinical reactions to specific foods. Clin Exp Allergy 1996;26:416-22.

26 Blanco C, Carillo T, Castillo R, Quiralte J, Cuevas M. Latex allergy: clinical features and cross-reactivity with fruits. Ann Allergy 1994;73:309-14 